\title{
A geografia da historiografia: o acesso à e o uso da documentação por Joaquim Felício dos Santos nas Memórias do Distrito Diamantino (1868)
}

Pedro Afonso Cristovão dos Santos*

Resumo: O presente artigo analisa a obra Memórias do Distrito Diamantino (1868), de Joaquim Felício dos Santos (1822-1895), sob o ponto de vista da localização das fontes e seu uso por parte do autor. O artigo investiga as possibilidades de escrita de histórias regionais no Segundo Império, refletindo sobre as potenciais limitações que o envio de documentos das províncias para a Corte (bem como as remessas para Lisboa, no período colonial, e para outros centros regionais, como Ouro Preto, no caso das Memórias analisadas) poderia trazer para os historiadores, e suas formas de superá-las. Tal delimitação geográfica, tanto do objeto de estudo da obra como dos arquivos à disposição do autor, poderia levar a uma consideração maior, por exemplo, das tradições orais locais como fontes. Por outro lado, a inserção do autor na sua região (como a de Joaquim Felício no Distrito Diamantino) se traduz em uma posição determinada a partir da qual o autor avalia e hierarquiza as evidências históricas com as quais trabalha. $\mathrm{O}$ artigo propõe, nessa linha, uma discussão sobre as evidências a partir das reflexões de François Hartog.

Palavras-chave: Historiografia. Brasil império. História regional. Fontes históricas.

"Doutor em História Social pela Universidade de São Paulo - USP. Professor da Universidade Federal da Integração Latino-Americana - UNILA. E-mail: pedroafonsocs@gmail.com. 
A geografia da historiografia: o acesso à e o uso da documentação...

No student of the history of historiography does his job properly unless he is capable of telling me whether the historian or historians he has studied used the evidence in a satisfactory way. (MOMIGLIANO, Arnaldo apud BOWERSOCK; CORNELL, 1994, p. XIV)

\section{Apresentação}

Ugo Tucci mostrou como Leopold von Ranke (1795-1886) pôde amealhar considerável coleção de documentos e obras raras em Veneza, e como o mercado destes artigos naquela cidade, ao lado das bibliotecas e arquivos (públicos e particulares), contribuiu para que tivesse acesso a um tipo de documento que lhe seria fundamental na escrita de suas obras: os relatórios dos embaixadores venezianos (TUCCI, 1999, p. 99-107). O estudo de Tucci ressalta o que pode ser, talvez, uma obviedade: a análise da historiografia demanda a consideração de como os historiadores tiveram acesso a suas fontes, e de quais puderam se utilizar na feitura de suas obras. À semelhança de Ranke, o século XIX é rico em exemplos que mantêm e reinventam a figura do historiador-viajante, cujas circunstâncias de vida permitem acesso a fontes e testemunhos que ajudam a moldar suas historiografias (o caso de Varnhagen, no Brasil oitocentista, pode ser visto sob essa ótica; cf. CEZAR, 2007). A geografia é, por conseguinte, parte indissociável da historiografia. As "cartografias" particulares desenhadas a partir das viagens nas quais, e por meio das quais, os historiadores conheceram suas evidências (termo polissêmico, que discutiremos a partir de HARTOG, 2011) parecem, pois, indispensáveis aos estudiosos de história da historiografia. Sem elas, fica dificultada a tarefa delineada por Arnaldo Momigliano na epígrafe anteriormente escrita (contida em BOWERSOCK; CORNELL, 1994, p. XIV): saber como o historiador/objeto de estudo utilizou-se de sua evidência. Como sabê-lo, sem saber onde, quando e em que circunstâncias o historiador viu o que viu (parafraseando o título do já citado estudo de HARTOG, 2011, grifos nossos)? 
Por outro lado, a limitação geográfica pode fazer parte da prática do historiador tanto quanto os deslocamentos. O que dizer de escritos cuja marca vem não dos arquivos e bibliotecas distantes visitados pelo autor, mas da restrição às evidências imediatamente disponíveis? Nenhuma documentação pode ser considerada completa; mesmo o mais fortuito historiador-viajante não pode reivindicar a obtenção de todas as fontes possíveis para seu estudo. A lacuna e a ausência são partes inerentes da "operação historiográfica". Neste artigo, propomo-nos a estudar ausências que têm a ver com a geografia, com as restrições contidas no lugar (geográfico) a partir do qual escreve o historiador. No caso, o historiador do local, do regional, confrontado com as evidências que seu espaço de escrita (simultaneamente objeto de estudo) lhe permite acessar.

Este historiador pertence ao contexto do Brasil oitocentista, e sua história local remete à sua terra natalícia: Joaquim Felício dos Santos (1822-1895), autor das Memórias do Distrito Diamantino, publicadas em livro pela primeira vez em 1868 . Na origem, as Memórias de Joaquim Felício saíram no jornal diamantinense $O$ Jequitinhonha, entre janeiro de 1861 e setembro de 1862. Instado a republicá-las no Diário do Rio de Janeiro, Felício procedeu a uma rigorosa revisão do texto em 1864, acrescentando os dois primeiros capítulos, e assinou a obra em primeiro de outubro daquele outubro desse ano. Em 1868, as Memórias receberam a primeira edição em livro, pela Tipografia Americana. A obra recebeu uma segunda edição em 1924, e ao longo do século XX adquiriu certo status de bibliografia básica sobre o Brasil, sendo reeditada em 1956 como o primeiro número da Coleção Brasílica das Edições O Cruzeiro (Rio de Janeiro); a edição seguinte, de 1976, foi o número 26 da Coleção Reconquista do Brasil, da Editora Itatiaia (Belo Horizonte), em parceria com a Edusp (São Paulo). A quinta edição (1978), pela Editora Vozes, de Petrópolis, com apoio do Instituto Nacional do Livro e do Ministério da Educação e Cultura, fazia parte da coleção Dimensões do Brasil, que incluía de autores coloniais (como o padre Simão de Vasconcelos) a Capistrano de Abreu (do Conselho Consultivo da coleção faziam parte, entre outros, Sérgio Buarque de Holanda, Gilberto Freyre e José Honório Rodrigues). 
A geografia da historiografia: o acesso à e o uso da documentação...

Joaquim Felício, nascido em 1822, na Vila do Príncipe, depois Serro (cidade vizinha a Diamantina), pensou seus escritos sobre a história da região de mineração diamantina sob um propósito inicial simultaneamente modesto e desafiador (NEVES apud SANTOS, 1956, p. 22): seu intuito principal seria orientar os mineiros de então (década de 1860), apontando quais minas e terrenos já haviam sido explorados; portanto, aos quais não valeria a pena dedicar-se e desperdiçar esforços. Por outro lado, pretendia registrar a história de um povo oprimido pela administração colonial (e depois imperial), um povo cuja história patenteava o absolutismo e o autoritarismo português, e, por último, do governo central do Brasil independente. Essa segunda temática garantiu à obra o público liberal do Rio, ensejando sua publicação no Diário do Rio de Janeiro e depois em livro. Felício tinha relações com o círculo liberal carioca, especialmente com Quintino Bocaiúva, colaborador e depois redator-chefe do Diário do Rio de Janeiro: seu romance histórico Acaiaca foi publicado, após sair n'O Jequitinhonha, na coleção Biblioteca Brasileira, dirigida no Rio por Bocaiúva (EULÁLIO, 1976, p. 15). No momento da publicação das Memórias, Quintino Bocaiúva era o redator-chefe do Diário (seu "ilustrado redator", declara Felício no início da obra, na nota "Ao leitor" das Memórias), assumindo sua direção em dezembro de 1865, quando tinha como seu braço direito Machado de Assis (BOCAIÚVA, 1986, p. 24). Quintino quase foi contemporâneo, ou ao menos caloiro, de Felício, pois veio para São Paulo em 1850, aos catorze anos (nascera no Rio de Janeiro), para iniciar os estudos no curso anexo à Faculdade de Direito do Largo São Francisco, onde Felício, naquele ano, se formava.

Distrito Diamantino era o nome dado à área de exploração de diamantes (descobertos no início do século XVIII) localizada na Comarca do Serro Frio, região do Vale do rio Jequitinhonha, no nordeste da capitania de Minas Gerais (separada da capitania de São Paulo desde 1720), posteriormente província. O centro administrativo do Distrito era o Arraial do Tijuco, ou Tejuco, que a partir de 1831 recebeu o nome que possui até hoje, Diamantina, desmembrada do Serro, antiga Vila do Príncipe. A demarcação do Distrito ocorreu em 1731, mas constantes expansões de seus limites foram efetuadas à medida que novas áreas de mineração 
de diamantes eram descobertas. De 1734 a 1739, a exploração de diamantes foi mantida proibida a particulares, e o Distrito teve administração própria. Em 1739, tem início a fase dos contratos, em que contratadores particulares arrendavam junto à Coroa o negócio de extração de diamantes, comprometendo-se a pagar uma remessa determinada ao rei. Em 1745 foi proibido o livre acesso ao Distrito, e em 1771 a Coroa assumiu o negócio de diamantes, pondo fim aos contratos. Passa a valer então a legislação do Regimento Diamantino, conhecido popularmente como "Livro da Capa Verde", um corpus de regras que aparece, em Joaquim Felício, bem como em outros autores, como símbolo maior do despotismo português na colônia. A partir desse momento, a administração do Distrito esteve a cargo da Junta Diamantina, subordinada à Administração Diamantina, em Lisboa. ${ }^{1}$

As Memórias do Distrito Diamantino são divididas em quarenta e dois capítulos, acompanhando, grosso modo, a cronologia administrativa do distrito. O livro parte da descoberta das minas no Serro Frio e acompanha as diferentes legislações a respeito da exploração mineradora na região, seguindo ainda a ordem dos governadores e intendentes responsáveis pela administração do distrito. Por outro lado, a obra é pontuada pelo que podemos chamar de narrativas da história social do distrito, como o capítulo $\mathrm{XV}$, que contempla a história de Xica da Silva, ou o capítulo XXXII, dedicado a "Isidoro, o garimpeiro; sua vida, prisão, martírio e morte", além de tratar, por todo o texto, do contrabando de diamantes. $\mathrm{O}$ capítulo XLII, último, inclui observações sobre os tipos sociais do "mineiro" e do "agricultor", contrastantes na vida social do distrito.

Procuraremos estudar nesse autor e obra a questão do alcance documental, ou do raio de arquivos e documentação que o autor poderia cobrir (especialmente quando se baseava essencialmente na documentação guardada na província sobre a qual escrevia), e o quanto esse alcance poderia marcar seu texto historiográfico. Buscaremos a tipologia das fontes utilizada por Joaquim Felício nas Memórias, bem como seu uso de cada tipo de documentação, pensando relações entre essa prática, os limites dos arquivos disponíveis a Felício e os limites (geográficos e cronológicos) que o próprio impôs ao objeto de seu escrito. 
A geografia da historiografia: o acesso à e o uso da documentação...

\section{Arquivos e províncias no Brasil imperial}

O movimento de direcionamento dos documentos das províncias para a Corte (já presente no período colonial, com o envio de arquivos para Portugal), que se acentua após 1838 (por iniciativa do IHGB, e ainda com a criação do Arquivo Público do Rio de Janeiro; cf. COSTA, 2000), envolvia basicamente documentos oficiais ou, no limite, memórias e crônicas, se não oficiais, com um caráter de obras que obedeciam a determinadas regras, mesmo que fluidas. Ou seja, estavam fora do alcance do que era remetido das províncias para a Corte, pela sua própria natureza, pois eram fontes que não se enquadravam ou não tinham como ser enquadradas naquelas que os arquivos da Corte guardavam, como panfletos, manuscritos particulares, e, principalmente, tradições orais. Assim, veremos nas Memórias do Distrito Diamantino o recurso a depoimentos orais, geralmente de pessoas idosas, guardadoras da memória antiga do Distrito, "documentos" que os arquivos centrais não tinham como recolher (ou, melhor dizendo, não se preocuparam em recolher, ou estavam fora de sua concepção de documento) e cuja participação na escrita da história poderia ser problemática, pela forma como a historiografia oitocentista lidava com as tradições orais. Desse modo, as províncias possibilitavam a um autor local um arquivo específico, mescla de documentação da burocracia oficial local, produção letrada (particular e regional) de outras épocas e fontes não escritas, tradições locais cuja incorporação ao texto histórico demandava do autor alguma forma de crítica da testemunha, validando-a ou não.

A pesquisa de Joaquim Felício para a escrita das Memórias deparou-se com os problemas relativos à limitação dos arquivos regionais. No primeiro dos apêndices incluídos por Alexandre Eulálio na terceira edição (1956) das Memórias, que é o primeiro artigo da obra saído n'O Jequitinhonha, de vinte de janeiro de 1861, Joaquim Felício dá a seguinte procedência dos fatos que relata:

[...] o que podemos afiançar aos nossos leitores, é a veracidade dos fatos que vamos publicar: a sua prova encontrarão em documentos existentes na Secretaria da Administração 
Diamantina, e quando recorrermos à tradição procuraremos o testemunho de pessoas fidedignas (SANTOS, 1956, p. 429).

Suas principais fontes viriam da documentação oficial local (excluindo, como veremos, toda aquela remetida a Lisboa) e de depoimentos diretos de testemunhas "fidedignas". José Teixeira Neves identifica algumas dessas testemunhas e ainda lembra que no próprio $O$ Jequitinhonha apareciam notícias de indivíduos centenários vivendo em Diamantina por volta de 1862, que seriam depositários confiáveis da memória local (NEVES, 1956, p. 22-23).

A esses dois conjuntos de fontes, deve-se somar o arquivo pessoal de Joaquim Felício e obras de outros historiadores. Entre essas, contamos a História da Fundação do Império Brasileiro (186468, parte, portanto, da revisão de Felício voltada à publicação das Memórias em livro), de João Manuel Pereira da Silva (1817-1897), que aparece como fonte propriamente, ou seja, tendo seu relato dos fatos usado por Felício (SANTOS, 1956, p. 61), e como fonte de documentos, pois Felício transcreve documento a partir de Pereira da Silva (SANTOS, 1956, p. 140) - além de oferecer interpretação dos fatos utilizada por Felício, no caso, considerações de Pereira da Silva sobre o absolutismo da administração colonial sobre o Distrito Diamantino (SANTOS, 1956, p. 55). Também são citadas as Memórias sobre o Quinto do Ouro de Minas Gerais, de José Antônio da Silva Maia, de 1827. Felício ainda menciona duas edições da Revista do IHGB, o volume 16, de 1853, onde saiu publicada uma Instrução de 1752, e o tomo 4, que continha biografia do Intendente dos Diamantes, Manuel Ferreira da Câmara Bittencourt e Sá, assinada por José Francisco Sigaud. ${ }^{2}$ Felício ainda utiliza os viajantes Auguste de Saint-Hilaire e John Mawe, e a História Geral de Varnhagen, que aparece em três momentos: dois deles são momentos em que Felício contesta o texto de Varnhagen. No terceiro, utiliza-o como fonte (SANTOS, 1956, p. 148).

$\mathrm{O}$ arquivo pessoal de Joaquim Felício aparece, por exemplo, no caso de "[...] uma exposição, que possuímos manuscrita, feita à coroa sôbre o estado nas minas por José da Costa Sousa Rabelo” (SANTOS, 1956, p. 278); ou em alguns pareceres em que "Possuímos manuscritos”, de vários mineiros à coroa sobre a questão do contrabando 
A geografia da historiografia: o acesso à e o uso da documentação...

de ouro (SANTOS, 1956, p. 279). Considerando ainda a menção a "Um velho manuscrito, que temos presente, e que atribuímos ao Dr. Plácido da Silva e Oliveira Rolim, irmão do inconfidente Padre José da Silva e Oliveira Rolim” (SANTOS, 1956, p. 115), bem como a "[...] um eloqüente sermão que possuímos manuscrito, como uma preciosidade” (SANTOS, 1956, p. 198), do Dr. Brandão, vigário da Vila do Príncipe, cremos que o arquivo pessoal de Felício possa ter sido amealhado junto a particulares. Felício também utiliza cartas particulares (SANTOS, 1956, p. 91-92 e p. 226, nota 40), que não diz se eram ou não de sua propriedade (cremos que não), mas que reforçam a possibilidade de ter obtido o consentimento ou mesmo a ajuda de conterrâneos para a escrita da obra.

O uso dos depoimentos diretos segue a preocupação com testemunhas "fidedignas" e, quando possível, oculares. Contamos quinze menções de Joaquim Felício a esse tipo de fonte, e em alguns casos aparecem expressões de validação, tais como: "[...] conforme narrou-nos uma testemunha ocular” (SANTOS, 1956, p. 362), ou o caso do sofrimento nas mãos das autoridades do garimpeiro (isto é, minerador ilegal, no vocabulário da época) Isidoro: "O que acabamos de narrar contaram-nos testemunhas fidedignas, imparciais, oculares" (SANTOS, 1956, p. 322).

Relacionadas aos testemunhos orais estavam, de certa forma, as "tradições". Para parte da historiografia oitocentista brasileira, as tradições, quando não podiam ser comprovadas documentalmente, deveriam ser excluídas dos textos historiográficos, vindo a servir, eventualmente, como material para obras literárias (OLIVEIRA, 2012, p. 2). Joaquim Felício menciona nas Memórias, segundo contamos, vinte e duas tradições. Sua posição, em geral, é por aceitá-las, ou ao menos consentir em apresentá-las. Em um dos casos, parte de uma tradição, busca sua comprovação e, feito isso, desmente trecho da História Geral de Varnhagen. É o episódio em que o Conde de Valadares entrega ao contratador (isto é, o arrendatário do contrato de extração de diamantes) João Fernandes Vieira uma ordem do rei de Portugal para que este deixasse o Arraial do Tijuco e partisse para Lisboa, sob pena de, desobedecendo, ser considerado inconfidente. É o início da ruína de Vieira, homem muito rico e importante, célebre por ter se casado com Xica da Silva. Joaquim Felício narra 
toda a dissimulação do Conde de Valadares para se aproximar de João Fernandes Vieira, postergando a entrega da ordem e obtendo muito ouro do contratador no meio-tempo.

O trecho no qual Felício relata o momento em que o Conde afinal notifica Vieira termina com remissão à seguinte nota de rodapé:

Podemos asseverar a autenticidade dos fatos, que de propósito narramos com todas as suas circunstâncias, e talvez demasiadamente. Nós os sabemos da tradição e testemunho de pessoas respeitáveis e fidedignas, que tivemos o trabalho de consultar, que os ouviram dos contemporâneos de João Fernandes, que os conheceram e foram testemunhas oculares. Ainda hoje existe um velho desse tempo, que confirma o que levamos dito. Fizemos esta nota por termos lido o seguinte na História do Brasil por Varnhagen:

“Em Minas o Conde de Valadares (1768-1773) zelou pela fazenda pública, evitou roubos e extorsões e fez respeitar a autoridade pública, apesar dos régulos e mandões [entre os quais se incluiria João Fernandes Vieira, um poderoso local], que haviam introduzido tal relaxação nos costumes, que a virtude era sufocada pela ambição, pela soberba e pelo orgulho; a riqueza fazia a honra e veneração popular; a vingança adquiriu e restabeleceu o respeito, e a grandeza do fausto era o único caráter da nobreza e fidalguia. O Conde de Valadares tinha grande compreensão e gênio indagador, constante e inalterável; foi prudentíssimo, desinteressado, reto, zeloso e de exemplar proceder”.

É assim que se escreve a história (SANTOS, 1956, p. 166).

Joaquim Felício partiu da tradição conhecida no Serro Frio sobre o papel do Conde Valadares no desterro de João Fernandes Vieira, averiguou-a (segundo diz) e pôde enfim contestar o retrato que Varnhagen desenha do Conde na História Geral. Varnhagen não deveria conhecer a tradição local; se a conhecia, optou por ignorá-la, o que pode ser compreendido levando-se em conta o capítulo da 
A geografia da historiografia: o acesso à e o uso da documentação...

História Geral em que está o trecho citado por Joaquim Felício. É a seção XLV do tomo II, que apresenta, de forma geral, uma defesa da centralização administrativa em detrimento dos poderes locais, o oposto do que defendia Joaquim Felício. O Conde de Valadares é, para Varnhagen, além de indivíduo exemplar, símbolo da necessidade do poder central para conter os desvios de costumes decorrentes do excesso de poder na mão dos "mandões" locais (como João Fernandes Vieira). O trecho transcrito por Joaquim Felício, que se encontra entre as páginas 251 e 252 da primeira edição (1857) do tomo II da História Geral, está copiado fielmente pelo autor mineiro, com um porém: as partes "[...] a virtude era sufocada pela ambição, pela soberba e pelo orgulho; a riqueza fazia a honra e veneração popular; a vingança adquiriu e restabeleceu o respeito, e a grandeza do fausto era o único caráter da nobreza e fidalguia [...]", e "[...] tinha grande compreensão e gênio indagador, constante e inalterável; foi prudentíssimo, desinteressado, reto, zeloso e de exemplar proceder [...]" estão entre aspas em Varnhagen. Pode-se argumentar que, se Varnhagen transcreve o trecho, o subscreve, mas a parte que de fato indignou Joaquim Felício é de um terceiro, não do futuro Visconde de Porto Seguro.

Não há referência direta em Varnhagen às fontes de onde extraiu as citações, mas a segunda deve pertencer (embora não esteja transcrita textualmente) à Instrução para o governo da capitania de Minas Gerais, de José João Teixeira Coelho. O texto, de 1780, é citado por Joaquim Felício nas Memórias (SANTOS, 1956, p. 56-57, 59 e 195), e, nos momentos em que o utiliza, Felício não lhe faz qualquer objeção como fonte, pelo contrário, trata-a como fidedigna. Quando contestar Varnhagen a respeito do pioneirismo da fundição de ferro no Brasil, em seção que mencionaremos mais à frente, Felício colocará questionamentos à fonte usada pelo historiador sorocabano, às motivações do autor de um panfleto que serviu de base à narrativa contida na História Geral. Mostrará que uma fonte tomada por Varnhagen como uma testemunha ocular fidedigna era, na verdade, fortemente interessada e parcial. Aqui, por outro lado, Felício não identifica a procedência ou não procura discutir o caráter apologético do trecho da Instrução que trata do Conde de Valadares, aspecto apontado por Laura de Mello e Souza, 
que mostra como os textos do século XVIII, referentes a Minas Gerais, "[...] omitem todo comentário crítico e se limitam a arrolar as virtudes morais dos governantes, não podendo ser diferente numa época em que a colônia sul-americana e a Metrópole integravam um só Império" (SOUZA, 2006, p. 176). A autora cita a seguir o mesmo trecho da Instrução usado por Varnhagen e criticado por Felício para mostrar como os governantes de então apareciam, na sua expressão, como "modelos de virtude pública".

Interessa apontar ainda que Joaquim Felício faz a discussão da divergência com Varnhagen no rodapé e não no corpo do texto - mostrando preocupação com a não interrupção da narrativa em caso de debate historiográfico. Se nesse caso Felício atestou a tradição, há momentos em que mostra desconfiança, como neste trecho:

Diz-se geralmente que os contratadores do primeiro e subsequente contratos sempre abusaram desta última condição [o limite de seiscentos escravos no trabalho de mineração], e que alguns deles mineraram com um número, que se tem elevado, até quatro mil escravos.

Não duvidamos que alguma vez se desse abuso, e mesmo constam de documentos oficiais reiteradas queixas de intendentes e fiscais contra os contratadores pela infração desta condição; não podemos, porém, capacitar-nos que seja verdadeiro tudo quanto reza a tradição a este respeito, atenta a vigilância que havia, para que não trabalhassem com escravos além dos capitados [seiscentos], a energia e zelo de muitos intendentes e fiscais, e sobretudo as providências que se deram para o rigoroso cumprimento do contrato e severidade das penas impostas à sua violação (SANTOS, 1956, p. 87).

Isto é, a tradição dava conta de abusos na legislação, que restringia a seiscentos o número de escravos que um contratador de diamantes poderia empregar, chegando a se falar em quatro mil escravos, mais de nove vezes o permitido (e alguns "documentos oficiais" corroborariam tal queixa). Esse parece mais um caso de verossimilhança histórica do que de constatação de um fato histórico comprovado 
A geografia da historiografia: o acesso à e o uso da documentação...

pelos documentos. Felício concorda que abusos existiam, mas lhe parece implausível que, com toda a vigilância existente, um contratador tenha conseguido chegar a ter quatro mil escravos em seu serviço. De todo modo, as tradições não eram descartadas, a priori, por Joaquim Felício, e mereciam pelo menos o benefício da dúvida.

Ao ouvir a "tradição e testemunho de pessoas respeitáveis e fidedignas", Felício compreende uma história que é visão, mas também audição (HARTOG, 2011, p. 144). Entretanto, fugindo à proposta micheletiana de ser o historiador um "visitante dos mortos e dos túmulos” (HARTOG, 2011, p. 150), Felício se apoia no testemunho dos vivos. São estes que lhe permitem devolver o morto (João Fernandes Vieira) a seu devido posto na história. O mergulho na história de Joaquim Felício é um mergulho não apenas nos arquivos e cemitérios, mas na vida social da localidade cuja história escreve. As tradições populares em Felício são, nesse caso positivamente, como para Michelet: "'em suma, verdadeira[s]" (HARTOG, 2011, p. 156).

As tradições orais às quais Felício não podia aferir certeza podiam servir-lhe, como no caso de Varnhagen com a lenda de Amador Bueno, ${ }^{3}$ de material para escritos literários. A tradição a respeito da descoberta de diamantes no Arraial do Tijuco é um exemplo. Nas Memórias, Felício afirma que "Não se sabe ao certo qual o lugar em que fora achado o primeiro diamante, atenta a variedade de tradições que há a respeito. Esta incerteza e variedade de tradições explica-se, e mesmo parece natural, se atendermos que os mineiros só se ocupavam com a extração [de ouro] e não conheciam ainda o diamante [...]", acrescentando ainda que "Não é menos difícil dizer quem fora o primeiro descobridor, ou antes, o primeiro conhecedor dos diamantes entre nós. Uns querem que fora Bernardo da Fonseca Lobo [...]. outra tradição diz que um frade, cujo nome não se declara” (SANTOS, 1956, p. 60). Em seu romance histórico Acaiaca (1866), que trata da descoberta dos diamantes como uma maldição sobre o Tijuco, Felício mistura as duas tradições que menciona nas Memórias: Bernardo da Fonseca Lobo foi o primeiro a extrair diamantes, mas, sendo um dos mineiros que "[...] só se ocupavam com a extração", não dá importância às pedrinhas. Um frade, em visita ao Tijuco, percebe-as na casa de Lobo, 
e, conhecedor de seu valor, o ludibria a presenteá-las, sem revelar seus conhecimentos a Bernardo, que as dá de boa fé (SANTOS, 1894, cap. XIII; atualizamos a grafia nas transcrições). ${ }^{4}$

Curiosamente, no romance, escrito sob a forma de um manuscrito histórico encontrado ao acaso, as tradições aparecem com poder de prova. Há na história um cientista capaz de produzir diamantes em laboratório, e a maneira do "manuscrito" fictício dar veracidade a isto é afirmando "Que o Dr. Medina fazia diamantes, é um fato que não podemos negar, porque aí está a tradição para atestá-lo” (SANTOS, 1894, p. 61). A tradição, corroborada por testemunhos fidedignos, servia para transmitir ao leitor toda a impressão de veracidade que conferiria à leitura da obra um impacto maior, malgrado o que houvesse nela de fantástico: "Cumpre agora explicar como o nome de Cajuby torna a aparecer nesta narração onde se tem visto fatos tão maravilhosos, mas que se não podem negar, a menos de querer-se contestar uma tradição constante, o testemunho de pessoas fidedignas" (SANTOS, 1894, p. 73). No romance, as tradições merecem crédito; as fontes em que se encontrariam "falsidades" e fábula são os relatos de viajantes estrangeiros, naturalistas satirizados no Acaiaca pelas descrições fantásticas que davam do que viam (SANTOS, 1894, em especial p. 85). Nas Memórias, Felício utiliza dois relatos de viajantes estrangeiros, os de Auguste de Saint-Hilaire e John Mawe. O primeiro aparece sempre como uma testemunha confiável; de Mawe, porém Felício põe em descrédito um cálculo do valor de diamantes vendidos por contrabando para a Europa (SANTOS, 1956, p. 98). Nem um caso, todavia, de descrição de aspectos naturais.

\section{A documentação e sua leitura por Joaquim Felício dos Santos}

O maior número de documentos que encontramos nas Memórias são aqueles que podemos classificar, seguindo a expressão que vimos Felício utilizar, de "oficiais". Sendo uma obra cujo eixo de sentido é dado pelo fato principal que organizou a vida no Distrito 
A geografia da historiografia: o acesso à e o uso da documentação...

Diamantino, a mineração, Joaquim Felício dedica sua atenção (e a do leitor) a acompanhar a evolução da legislação e das políticas reais em relação à mineração, que acarretavam ordenações de todo o restante da vida social. A obra se estrutura de fato pela sequência dos governantes a que o Serro Frio esteve sujeito, primeiro os governadores da capitania, aos quais se somam depois os intendentes gerais do Distrito Diamantino (isto é, após a criação da Intendência Geral dos Diamantes, em 1734, que aparece no quarto dos quarenta e dois capítulos); Felício procede procurando narrar os fatos mais notáveis e importantes de cada governo. $\mathrm{Na}$ verdade, como sua história procura mostrar a opressão sobre o povo do Arraial do Tijuco, um governo pobre em acontecimentos seria um governo em que poucas manifestações dessa opressão seriam observadas - como se, de forma geral, o estofo da história fosse de violências. Por isso, assinala Felício: "Disse um escritor: - Feliz o povo que não tem uma história” (SANTOS, 1956, p. 276). Há a frase atribuída a Montesquieu, "Heureux le peuple dont l'histoire est ennuyeuse" (feliz o povo cuja história é monótona), que pode ser a inspiração de Felício aqui.

Numa chave mais ampla, a obra segue as sucessivas legislações que regularam a mineração, ou melhor, a forma de a Coroa obter sua parte da mesma (isto é, cobrança de quinto, casas de fundição, capitação, mineração por contrato e a famosa Real Extração, regulada pelo temido Regimento Diamantino, ou Livro da Capa Verde, máxima expressão do despotismo real para Joaquim Felício ${ }^{5}$ ). A legislação real é o fio condutor da obra, com contraponto das reações do povo ao que o governo impunha; daí constarem frequentemente alvarás, decretos, portarias etc., de um lado, e as petições e representações dos moradores do Arraial do Tijuco, de outro.

Como dissemos anteriormente, Joaquim Felício afirmou, no primeiro artigo escrito para O Jequitinhonha do que viriam a ser as Memórias, que, além do testemunho de pessoas fidedignas, contou com os documentos da Secretaria da Administração Diamantina. Uma observação no romance Acaiaca pode ajudar a compreender a formação desse arquivo. Em uma das intervenções voltadas para conferir verossimilhança ao romance, o "editor" do "manuscrito" afirma, em nota de rodapé, a respeito de uma portaria transcrita no texto: 
Não possuímos e nem sabemos onde existem os livros, onde se mandou registrar esta portaria. E também não a encontramos no arquivo da extinta administração diamantina, para onde o Dr. Antônio Ferreira do Vale e Melo, quando nomeado intendente, trouxe todas as portarias expedidas anteriormente à sua criação (SANTOS, 1894, p. 107. A portaria transcrita no romance é uma versão alterada da portaria verdadeira sobre a descoberta de diamantes, transcrita nas Memórias; SANTOS, 1956, p. 61).

Antônio Ferreira do Vale e Melo era ouvidor-geral da Vila do Príncipe (exercendo autoridade sobre a região dos recém-descobertos diamantes) desde ao menos 1729 , e o regimento de 26 de junho de 1730 o nomeou, e a seus sucessores, "superintendentes de todas as terras diamantinas da comarca” (SANTOS, 1956, p. 62); o superintendente seria o equivalente do intendente, quatro anos antes desse cargo ser criado (quando da criação, inclusive, o intendente assumiu as atribuições do ouvidor-geral como superintendente; SANTOS, 1956, p. 70). Vale dizer que Júnia Ferreira Furtado, no seu estudo recente sobre o Regimento Diamantino, publicado em 1996, afirmou que a documentação da Intendência do Diamante já não existe mais, "[...] queimada provavelmente durante os trabalhos de recuperação do prédio, que atualmente abriga a Prefeitura e a Câmara da Cidade” (FURTADO, 1996, p. 29).

De todo modo, se for considerada válida a informação no Acaiaca, a Secretaria da Administração Diamantina, principal arquivo consultado por Joaquim Felício, deve ter sido estabelecida após junho de 1730, e recebeu os documentos oficiais anteriormente à sua criação. A ordenação da administração diamantina marca a baliza cronológica das Memórias. Em artigo seguinte ao inaugural publicado n'O Jequitinhonha, agora de 29 de janeiro de 1861, também incluído como apêndice na terceira edição das Memórias, Felício explica o marco inicial dos escritos, 1729:

É do ano de 1729 que começam estes apontamentos; por que foi quando na Comarca se conheceu a existência de um Distrito Diamantino. Até 1734, não estavam bem definidos 
A geografia da historiografia: o acesso à e o uso da documentação...

os seus limites, e todos os Alvarás, portarias, Bandos e Ordens, que se expediam sobre a nova mineração, só falavam em córregos e ribeiros de onde se extraem diamantes na Comarca do Serro Frio (SANTOS, 1956, p. 429).

Destarte, uma vez delimitada claramente a região, o objeto do autor também ganhou corpo. E o critério geográfico permanece ao longo da obra. Por isso, Felício julga necessário se justificar quando vai tratar da participação dos eleitores do Distrito Diamantino na escolha dos deputados mineiros às cortes, em 1821. Já no índice do capítulo, o XXXVII, aparece: "O autor entende dever acompanhar os eleitores da comarca até Vila Rica, sem apartar-se de seu assunto”, e assim o justifica:

Enquanto dão-se estes acontecimentos nada tem ocorrido de importância no Distrito Diamantino, que mereça ser referido; por isso aproveitaremos a oportunidade para seguirmos os nove eleitores da comarca até Vila Rica, onde vão concorrer para a nomeação dos Deputados às cortes pela capitania de Minas. Com esta digressão julgamos que não perdemos o fio da história do Distrito, porque acompanhamos os seus representantes. Os fatos sucedidos na capital pertencem de alguma forma às memórias, que vamos escrevendo. Demais é agradável recordarmo-nos dos primeiros tempos de nossa independência, visto que o presente só nos oferece a luta de paixões e interesses pequeninos, pela degradação a que entre nós tem descido o sistema representativo (SANTOS, 1956, p. 356, grifos nossos).

Sair da comarca do Serro Frio equivalia a uma "digressão", cabível porque, primeiramente, nada ocorria de notável no interior da comarca (se acontecesse, teria preferência, ao que parece). Felício julga não perder o "fio da história" ao seguir os representantes do Distrito até Vila Rica, embora não precise bem porque ("Os fatos sucedidos na capital pertencem de alguma forma às memórias"). O contraste com o atual (isto é, década de 1860) momento político parece o grande móvel do capítulo, de fato. E, vale notar, Felício 
teve como fontes para esse capítulo o que "ouvimos de testemunhas oculares e fidedignas” (SANTOS, 1956, p. 356, grifos nossos), os próprios representantes da comarca, supomos, mostrando que seu acesso às fontes quase sempre se limitava ao que estivesse (arquivos ou pessoas, isto é, testemunhas) no Distrito Diamantino. Note-se ainda o limite talvez mais distante atingido pela geografia das Memórias: Vila Rica.

Se a geografia determina fortemente o objeto nas Memórias, a cronologia não se intimida diante da história contemporânea. Felício chega a seus dias atuais e trata de pessoas ainda vivas ou com parentes vivos. É o caso de seu relato da ascensão e ruína da família Caldeira Brant, ainda então presente em Diamantina, provavelmente do círculo de amizades de Felício. ${ }^{6}$ Ali o autor advoga total imparcialidade:

Vamo-nos aproximando da época contemporânea. Os fatos tornam-se mais abundantes, a tradição mais clara. Das pessoas de que temos de falar neste escrito algumas ainda vivem, de outras há descendentes, parentes, amigos, ou conhecidos. Mas nada pretendemos ocultar nem desculpar: é o dever do narrador (SANTOS, 1956, p. 103).

As Memórias terminam com as últimas legislações em vigor a respeito dos terrenos diamantinos, no caso, uma lei de 1852, que alterava decreto de 1845: "[...] lei que julgamos excelente, e que ainda poderá ser melhorada se forem adotadas as ideias de um projeto, que atualmente existe na Câmara dos Deputados, e for pelo Governo melhorado o sistema da atual administração” (SANTOS, 1956, p. 403). A história articula-se então como o longo e tortuoso caminho que os moradores do Distrito Diamantino percorreram, do despotismo dos tempos coloniais à vida sob leis mais justas.

$\mathrm{Na}$ apresentação ao leitor de sua pesquisa com as fontes, Joaquim Felício usa expediente comum no século XIX: a utilização de expressões como "temos à vista", ou "temos presente", antes de tratar de um documento. Como em: "[...] uma carta particular, que temos à vista e da qual transcreveremos alguns trechos [...]” (SANTOS, 1956, p. 91. Dentre os muitos casos de uso daquelas expressões nas 
A geografia da historiografia: o acesso à e o uso da documentação...

Memórias, podemos citar ainda p. 73, p. 115, p. 146, p. 306). Essas expressões acabam por conferir credibilidade ao relato do autor, pois a transcrição ou o resumo do documento que geralmente lhes sucede é apresentado ao leitor como uma cópia fiel da fonte que o historiador tem à sua frente. Cremos que, em certo sentido, ocorre também uma presentificação da própria escrita da história nesses casos. Estudos recentes têm trabalhado os recursos utilizados pelos historiadores oitocentistas para dar um sentimento de presença ao leitor, isto é, fazê-lo presente à cena narrada no texto historiográfico (por exemplo, VARELA, 2012). Expressões como "temos à vista" tal documento, assim nos parece, colocam o leitor na presença do historiador no momento em que compõe seu texto, presentificam a própria escrita da história. É evidente que os documentos poderiam ser confrontados por outro estudioso que consultasse os mesmos arquivos, mas essa forma de escrita estabelece a confiabilidade da transcrição apresentada. Desse modo, o historiador assegura ao leitor que a transcrição do documento será fiel, pois não a faz de memória ou a partir de relatos de terceiros, mas "tendo presente", tendo diante de si a fonte que transmite a seus leitores.

Do ponto de vista da construção do texto, nos parece que a posse, ou a consulta pessoal (o ter ou o ter visto pessoalmente), funcionava como meio de comprovação da existência e da veracidade das afirmações feitas sobre o conteúdo da fonte, garantindo-se, evidentemente, a autenticidade da mesma. O ter visto pessoalmente aparece como meio de comprovação da existência de uma fonte. Alguns exemplos desse procedimento podem ser lidos no primeiro tomo da História Geral de Varnhagen. Em meio ao relato da invasão da Bahia pelos holandeses, no século XVII, Varnhagen menciona uma estampa gravada na Holanda comemorando a invasão de Piet Heyn, e afirma, em nota: "O original dela vimos em Amsterdã, em casa do bibliófilo Muller, em setembro de 1853" (VARNHAGEN, 1854, p. 353). Em outro momento, a presença do autor como testemunha ocular da documentação serve mesmo de comprovação para o que escreve. Sobre um suposto plano do Cardeal D. Henrique, sucessor de D. Sebastião, de se casar para manter a coroa em Portugal (acabaria passando à cabeça de Felipe II de Espanha), Varnhagen afirma, em nota: "A tal respeito vimos em Espanha 
uma carta autógrafa do cardeal-rei [D. Henrique] anunciando a Felipe II o seu projeto" (VARNHAGEN, 1854, p. 279). A questão do olhar no projeto historiográfico do IHGB aparece desde cedo, embora referido, em geral, a localidades geográficas que pudessem ser consultadas in loco, para dirimir dúvidas existentes nos textos. Entretanto, cremos poder estender essa lógica para a consulta a documentos, afirmando, com Manoel Luiz Salgado Guimarães, que "O olhar assegura então a possibilidade de prova" (GUIMARÃES, 2007, p. 112). O historiador é testemunha, não do fato que relata, mas da existência e do conteúdo do registro que apresenta ao leitor como fonte de informação e de credibilidade de sua narrativa.

\section{O alcance documental das memórias}

Os limites geográfico e cronológico da obra marcam também seu alcance documental, isto é, o raio de arquivos e fontes que seu autor cobrirá. Restringindo o Distrito Diamantino como o teatro das ações de que falará, e a cronologia de 1729 até seus dias atuais, década de 1860, Felício utilizou, como vimos, os arquivos da Secretaria da Administração Diamantina como sua principal fonte para os documentos oficiais sobre seu objeto. Contamos a menção a sessenta e cinco documentos oficiais nos quarenta e dois capítulos das Memórias, entre bandos do governador da capitania, portarias, alvarás, decretos, ordens régias, petições e representações dos moradores etc. As lacunas na pesquisa de Felício aparecem, de fato, no caso de documentos importantes para sua narrativa que não se encontravam no Distrito Diamantino.

E isso não apenas para os documentos que haviam sido remetidos a Lisboa. Felício afirma não ter como calcular os quilates de diamantes extraídos dos dois primeiros contratos, "[...] por não termos presentes os Livros das Entradas dos Diamantes para o Cofre [...]”, explicando, em nota de rodapé: “[...] estes livros eram cinco, que se achavam na Secretaria dos Terrenos Diamantinos, e foram remetidos para Ouro Preto, por ordem do Inspetor da Tesouraria da Província, de 4 de fevereiro de 1847”. A solução encontrada por Felício para oferecer uma estimativa é "[...] um pequeno folheto 
A geografia da historiografia: o acesso à e o uso da documentação...

anônimo, que corre impresso, do ano de 1821, intitulado: Refutação da Proclamação de Manuel Ferreira da Câmara Bittencourt e Sá, geralmente atribuído ao Dr. José Vieira Couto [...]”, complementado com trecho do Tratado dos Diamantes e Pedras Preciosas, de John Mawe, que viajou pelo Serro Frio em 1807 e, além de naturalista, era negociante de diamantes, segundo Felício (SANTOS, 1956, p. 96, grifos do autor).

Mas seu maior problema parece ter sido, de fato, com os documentos enviados a Lisboa. Caio Boschi (1998) relata a existência de 25 fontes referentes à comarca do Serro Frio e onze referentes a Diamantina, em Portugal, quando de sua pesquisa. Além de outras que pudessem interessar à pesquisa de Joaquim Felício, como as da Vila do Príncipe ou Ouro Preto, ou os papéis sobre os impostos de capitação ou as casas de fundição, já representa um bom número de documentos, os quais, se não houvesse cópias no Distrito Diamantino, estariam inacessíveis a Felício. Por exemplo: um relatório de 1757, de Antônio Lourenço Costa, oferecido ao Intendente, contando dez anos de viagens suas pelos sertões da região, para pretender junto ao rei o título de descobridor de diamantes. Felício não conheceu o relato: "Não possuímos este relatório, que devia ser bem curioso: foi provavelmente remetido para Lisboa" (SANTOS, 1956, p. 149; Caio Boschi não menciona documento de Antônio Lourenço da Costa entre as fontes que encontrou sobre Minas Gerais em Portugal. Teria o relatório se perdido?). Vale dizer que, pelo Regimento Diamantino, instituído em 1771, a Junta Diamantina, que administrava o Distrito, reportava-se diretamente à Administração Diamantina em Lisboa, criando uma comunicação direta com o reino (SANTOS, 1956, p. 207). É assim que, não tendo havido cópia, ou "traslado", os documentos quedavam fora da província no momento em que escreveu Joaquim Felício, como é o caso da devassa contra o Intendente João Inácio, sobre a qual Felício lamenta: "Sentimos não ter podido ler os atos desta devassa. Foram remetidos, sem ficar traslado, para Lisboa, que foi onde se abriram as inquirições” (SANTOS, 1956, p. 264).

Felício contrabalanceia os documentos oficiais com as tradições, testemunhos ou folhetos, como vimos anteriormente. No seu uso dos documentos oficiais, transcrições são muito frequentes. 
Seu propósito poderia ser dar a conhecer a legislação ou a decisão do governo em algum caso, ou ainda expor o que considerava o absolutismo e despotismo do governo em relação aos moradores do Tijuco (além de transcrever certas peças por "curiosidade", por exemplo. SANTOS, 1956, p. 100). Sobre a confiabilidade dos documentos oficiais quando forneciam descrições do Tijuco, Felício poderia levantar dúvidas, como faz no caso de um relatório sobre “o estado da mineração diamantina no ano de 1813", enviado pelo Intendente de então, Manuel Ferreira da Câmara Bittencourt e Sá, à Junta administrativa de Lisboa. O relatório dá uma perspectiva ruim para a possibilidade de extração na região, ao que contrapõe Felício, após transcrever três parágrafos do documento: "Tal era o conceito que Câmara fazia do Jequitinhonha em 1813; entretanto foi daí que nos anos posteriores extraiu as melhores remessas de diamantes, que fez para a corte. Hoje ainda é o rio mais rico do Distrito Diamantino" (SANTOS, 1956, p. 304-305).

As transcrições colocavam o problema da interrupção da narrativa. Em certo momento, Felício para e justifica suas transcrições, mostrando consciência do efeito disruptivo das mesmas sobre a narrativa:

Preferimos, sempre que se nos oferece ocasião, transcrever textualmente as disposições das leis a resumi-las: a linguagem do despotismo tem certa força e energia, que não será fácil imitar nos nossos tempos. Desculpe-nos, pois, o leitor qualquer excesso de transcrições (SANTOS, 1956, p. 175).

As transcrições justificam-se porque o autor não se vê capaz de transmitir "a linguagem do despotismo". O documento fala por si toda vez que o historiador for incapaz de imitá-lo, de mimetizar seu conteúdo. Mas o pedido de desculpas final demonstra o entendimento de Felício de que as transcrições comprometiam o andamento da narrativa. Na verdade, o termo recorrente em Felício é "narração", e são constantes suas preocupações com "digressões". Vimos anteriormente como acompanhar os representantes do Serro Frio a Vila Rica, na ocasião da escolha dos deputados mineiros às cortes, foi entendido por Felício como uma "digressão", e as 
A geografia da historiografia: o acesso à e o uso da documentação...

Memórias contam vários outros exemplos. Após relatar, seguindo um folheto, a destinação dada na corte portuguesa aos diamantes extraídos do Distrito, Felício retoma com "Voltemos à nossa narração" (SANTOS, 1956, p. 185). Talvez o principal momento de expressão da tensão que envolvia transcrições, digressões e a narração seja o relato dos festejos da população do Tijuco em homenagem ao Governador da capitania, que viera destituir e abrir sindicância contra o Intendente João Inácio, visto pelo povo como despótico. Escreve Felício:

Vamos transcrever, terminando este capítulo, uma pequena descrição, que possuímos manuscrita, dos festejos que por esta ocasião se fizeram na Conceição.

Precisamos pedir desculpa ao leitor por descermos muitas vezes a minuciosidades, que parecerão inúteis. Com esta publicação entrou muito em nosso intuito mostrar os costumes dos tempos passados; a nada há que faça melhor conhecê-los, que a descrição das festas e espetáculos públicos; eles são a expressão genuína das ideias e sentimentos da época. Por esta mesma razão temos muitas vezes preferido à narração dos fatos, a transcrição de documentos, em que eles vêm relatados. Dada esta satisfação julgamos poder apresentar a descrição prometida (SANTOS, 1956, p. 264-265).

Esse trecho parece revelar que Felício não via suas Memórias como esse gênero seria normalmente entendido, pois, pela definição do dicionário Moraes Silva de 1831, as memórias poderiam ser espaços para miudezas, para minúcias:

As memorias desenvolvem miudamente os factos e suas causas; discutem os que são duvidosos, determinão e verificão datas, copião documentos, etc. O seu estilo deve ser simples, livre, corrente, e desaffectado, e não admitte o ornato, a nobreza, e a elevação da Historia. O nome de memorias, que indica o fim deste genero de escritura, mostra tambem, de algum modo, qual deve ser o seu caracter. Quem quer conservar, ou deixar em memoria os successos publicos do 
seu tempo, escreve tudo, escreve os factos principaes, e os menos principaes, nota as causas e as consequencias, etc. (SILVA, 1831, p. 301).

Talvez o problema aqui fosse com o fato a ser relatado com "minuciosidade": os festejos, fatos relativos a costumes, ideias e sentimentos. Assim, o problema seria introduzir uma preocupação quase antiquária (MOMIGLIANO, 2004, cap. 3) numa narração eminentemente política, isto é, interpor um momento de descrição sistemática numa narrativa cronológica linear.

Felício não chega a ter a preocupação memorialista por completo, se tomarmos por base a definição anteriormente exposta, pois não age como "Quem quer conservar [...] [e] escreve tudo". Em vários momentos seleciona entre os documentos e casos que pode apresentar, quando julga que só precisa de um exemplo daquilo que pretende transmitir ao leitor. Quando procura expor os motivos fúteis que as autoridades usavam como subterfúgio para instaurar processos no Distrito Diamantino, sob alegação de combaterem a mineração ilegal de diamantes, Felício escreve: "Temos à vista alguns dos processos daquele tempo. Seria longo, fastidioso e inútil narrar o que eles contêm. De um deles, que abrimos, quase sem escolha, consta que [...]” (SANTOS, 1956, p. 73). Em nossa leitura, suas Memórias contêm a preocupação com a fluência da "narração", uma atenção à linearidade e à sequência cronológica dos eventos, assim como o acompanhamento dos fatos "notáveis" ocorridos em cada unidade em que se divide a narrativa, normalmente a sequência de administradores do Tijuco. Há um eixo, dado pelas regulamentações que o governo impôs ao povo do Tijuco, e as reações deste.

De fato, são poucos os momentos que Felício dedica à discussão de alguma questão historiográfica. Seus questionamentos a visões contidas em tradições ou fontes são breves, sem grande argumentação. $\mathrm{O}$ grande momento em que realmente se dedica a uma argumentação voltada à questão duvidosa é no capítulo em que trata do estabelecimento da fundição de ferro no Serro Frio. Após relatar a produção das primeiras barras de ferro e sua celebração em regozijos públicos pelo povo do Tijuco, Felício transcreve o trecho da História Geral em que Varnhagen relata o mesmo fato, 
A geografia da historiografia: o acesso à e o uso da documentação...

de perspectiva completamente diferente, afirmando que as celebrações públicas serviam apenas para disfarçar o efetivo fracasso da fundição. A partir daí, até o fím do capítulo (o XXVIII), Joaquim Felício contestará a versão varnhageniana (sobre a polêmica, cf. CEZAR, 2005).

\section{Considerações finais}

As Memórias do Distrito Diamantino, de Joaquim Felício dos Santos, expõem questões relativas à escrita da história nas províncias no Segundo Reinado. Trabalhamos aqui, sobretudo, os problemas referentes à documentação. Que fontes permaneciam nas províncias ao alcance dos autores locais? Estas lhes permitiam contestar versões de autores escrevendo a partir de outros lugares (simbólicos e geográficos)? O uso das tradições, em particular, parece mais aceito como fonte. O peso da localidade, do conhecer ao longo da vida os guardiões da tradição, moradores do local como o autor, teria algum impacto nisso?

Vale dizer que Joaquim Felício dos Santos não reclama de arquivos enviados à Corte, uma consequência possível, como afirmamos no início, do projeto historiográfico do IHGB (o tomo I da Revista do Instituto já vinha com uma "Lembrança do que devem procurar nas províncias os sócios do Instituto Histórico Brasileiro, para remeterem à sociedade central do Rio de Janeiro", elaborada pelo então secretário Januário da Cunha Barbosa) e do estabelecimento do Arquivo Público do Rio de Janeiro, ambas as instituições inauguradas em 1838. Autores de histórias provinciais no século XIX, como Gonçalves Dias (DIAS, 1853) e João Francisco Lisboa (LISBOA, 1976, em especial p. 62), ambos escrevendo sobre o Maranhão, descreveram a situação gerada pela transferência de documentação para o Rio de Janeiro, marcada pelos desfalques nos arquivos locais (embora Lisboa não visse o traslado com maus olhos, em razão do mau estado dos arquivos no Maranhão). O processo de transferência de documentos para a Corte antecedeu o IHGB, começando, segundo José Honório Rodrigues, já em 1825, com decreto de D. Pedro I (RODRIGUES, 1969, p. 54). 
O problema maior de Felício ainda era consequência do período colonial, do envio de documentos a Lisboa. Documentos, no caso, "oficiais" (na terminologia de Felício), mas que nem por isso escapavam da desconfiança do autor, como vimos anteriormente. Panfletos, memórias e, em particular, tradições orais, demandavam também juízo crítico para sua utilização. A "fidedignidade" das testemunhas, sua posição em relação ao que narravam (se eram ou não testemunhas "oculares"), sua isenção em relação àquilo (ou a quem) de que falavam, faziam parte desse juízo crítico. Juízo consideravelmente dependente do olhar e da credibilidade do historiador: não se revela, por exemplo, a identidade das testemunhas que narram as tradições; sua fidedignidade perante o leitor provém do autor, ou de um pacto deste com aquele que lê. A evidência de Joaquim Felício é a região, é o Distrito Diamantino, suas repartições e sua população, somadas à sua coleção particular de livros e manuscritos. O mundo exterior das ruas e instituições diamantinas e o mundo interior do gabinete do historiador. Com efeito, a atenção dada ao olhar deve ser compartilhada com o ouvir, que possibilita o registro das tradições orais. "Se a história é visão, ela é também audição", aponta Hartog (2011, p. 144), trabalhando com uma perspectiva de longo prazo, partindo desde as concepções antigas de evidência e testemunho, e se detendo, no momento da citação já exposta, ao século XIX de Michelet.

Pois, segundo Hartog, "[...] para Michelet, o historiador é não só um mergulhador, visitante dos mortos, o viajante com olhar-participante, mas ainda deve ser dotado de ouvido porque a história fala" (HARTOG, 2011, p. 154-155). Joaquim Felício deixou falar, como vimos, os documentos da administração colonial, cuja linguagem expressava o despotismo melhor do que ele, memorialista, poderia fazer. Hartog vê, nessa linha, duas abordagens distintas na França do século XIX: Augustin Thierry, que deixa falar os documentos oficiais e provenientes da burguesia, e Michelet, para quem o historiador deve "saber ouvir a história" (HARTOG, 2011, p. 155), pois busca não o Estado ou a classe dominante (produtores de ampla e articulada documentação), mas o povo, aquele que sussurra, balbucia, articula e formula com dificuldade o que tem a dizer. É nesse registro que entra, na historiografia romântica 
A geografia da historiografia: o acesso à e o uso da documentação...

francesa de meados do século XIX, a tradição. "'Tradição oral', a crença popular é também 'tradição nacional'” (HARTOG, 2011, p. 155), com um detalhe (na visão micheletiana): para compreender o povo é preciso ser do povo ou, ao menos, ser compassivo em relação a suas vivências. Faria Joaquim Felício uma combinação dos dois exemplos, deixando falar documentos oficiais e sabendo ouvir tradições?

Silvio Romero, escrevendo em 1888, comparou Joaquim Felício à historiografia romântica, mas a Thierry, e não Michelet. Para Romero:

Felício dos Santos traz à memória Aug. Thierry, não pela sobriedade majestosa do estilo, senão pelo dom da evocação pinturesca dos fatos e das personagens históricas. - O livro [refere-se às Memórias do Distrito Diamantino] é delicioso de naturalidade, de singeleza, de tom realístico.

A vida dos sertanejos mineiros, da região diamantina, aparece, durante dois séculos, da segunda metade do século XVII à primeira do século XIX, em plena movimentação.

Vê-se que é obra de legista, mas legista que educou a fantasia no romance.

Os homens ali vivem e se movem (ROMERO, 1960, p. 1586).

Francisco Iglésias manterá a vinculação ao Romantismo, considerando as Memórias do Distrito Diamantino como um "[...] livro singular na bibliografia histórica, como algo único, nunca repetido, nem imitado [...]", embora fosse "exemplo típico da historiografia romântica” (IGLÉSIAS, 2000, p. 106-107). A “evocação pinturesca dos fatos”, na terminologia de Romero, é o sinal indefectível do Romantismo, ligado à cor local tão almejada (CEZAR, 2004). Porém, se Romero preferiu ver Thierry ao invés de Michelet em Joaquim Felício, poderia ter seguido a direção contrária: a "vida dos sertanejos", sua "plena movimentação", os "[...] homens [que] ali vivem e se movem [...]", são descrições que trazem à mente o elemento que Michelet julgava ter introduzido na história da França: a vida (HARTOG, 2011, p. 163). 
Como pôde Felício captar com tal "tom realístico" o caráter do povo, dos sertanejos do Distrito que descreve? Sua fantasia educada no romance lhe forneceria algumas ferramentas, por certo, mas o que dizer da parte que cabe à pesquisa histórica? Pôde Felício ver e ouvir o que o Distrito tinha a lhe mostrar e dizer, e depois fazer presente a seus leitores o que enxergou? Retomamos nosso questionamento: que efeito tem o vínculo de Joaquim Felício com sua terra natal sobre sua tentativa de escrever as memórias dessa terra? É de seu conhecimento da localidade, da população, que lhe vem as pistas das tradições, das cartas, dos manuscritos, o acesso à documentação oficial? É desse conhecimento e de sua posição na comunidade local que the vem o lugar a partir do qual julgar credibilidades e fidedignidades? Permite-lhe ver motivos e motivações, e hierarquizar sua sociedade como fonte?

Joaquim Felício não é um historiador-viajante. Não podemos supor, por isso, que não tenha obtido livros e materiais de fora do Distrito (como as revistas do IHGB de que se vale, num exemplo simples). Mas Felício não foi a Lisboa obter os documentos que não encontrava na província, e teve dificuldades, inclusive, com documentos que estariam em Ouro Preto. Por outro lado, talvez muito de sua escrita historiográfica venha justamente de seu enraizamento no Distrito Diamantino. O que o levou a escrever suas Memórias do modo como escreveu parece ter a ver com uma educação do olhar que o convívio, a estadia longa, a posição social (com todos os pré-juízos que esta pode implicar), o nascer e crescer no lugar concedem, por oposição a uma passagem, a um olhar externo. A própria desconfiança em relação aos textos de viajantes não deixa de estabelecer essa distinção entre os do Distrito e os de fora. Joaquim Felício escreve uma história da província, e o duplo significado da preposição, indicando o objeto bem como o lugar de onde pesquisa e escreve o autor, talvez seja chave para compreendermos como buscou e utilizou suas evidências. 
A geografia da historiografia: o acesso à e o uso da documentação...

\section{THE GEOGRAPHY OF HISTORIOGRAPHY: THE ACCESS TO AND THE USE OF THE SOURCES BY JOAQUIM FELÍCIO DOS SANTOS IN MEMÓRIAS DO DISTRITO DIAMANTINO (1868)}

Abstract: The article analyzes the book Memórias do Distrito Diamantino (1868), by Joaquim Felício dos Santos (1822-1895), from the perspective of the localization and use of the historical documents by the author. The article investigates the possibilities of writing regional history in the Second Empire through a reflection on the potential limitations that the sending of documents from the provinces to Rio de Janeiro (or Lisbon, in the colonial period, or to regional administrative centers like Ouro Preto, as in the case of the Memórias) could bring to historians, and how they attempt to overcome these limitations. Such geographical delimitation, both concerning the subject of regional history and the local archives used to its writing, could lead to a greater appreciation, for instance, of the oral traditions as sources. On the other hand, the author's insertion in the local society (such as Joaquim Felício's insertion in the region studied in the Memórias) translates itself in a determined position from which the author could evaluate and hierarchize the historical evidences with which he works. The article proposes, in this line, a discussion about evidences from the reflections of François Hartog.

Keywords: Historiography. Second Empire. Local History. Historical sources.

\section{Notas}

${ }^{1}$ Uma boa síntese da organização do Distrito Diamantino no período colonial encontra-se em (FURTADO, 1996, p. 25-34).

2 José Francisco Xavier Sigaud (1796-1856), francês de Marselha, doutor em Medicina, chegou ao Brasil em 1825, fugindo da perseguição antibonapartista na França. Biografia Disponível em: http://www.dichistoriasaude.coc.fiocruz. br/iah/P/verbetes/sigjoxav.htm. Acesso em: mar. de 2013.

${ }^{3} \mathrm{~A}$ tradição diz respeito ao governante paulista Amador Bueno, que teria sido aclamado rei pela população de São Paulo em 1640, após a restauração bragantina em Portugal (a separação da Espanha, que pôs fim à União Ibérica). Bueno teria, então, recusado a coroa, preferindo declarar-se leal ao rei de Portugal. Varnhagen não encontrou subsídios para este fato, de modo que sua presença na História Geral é passageira e sempre ponderada por condicionantes. Em compensação, escreveu uma obra literária contando esta história, Amador Bueno ou a Coroa do Brasil, em 1641. Drama épico-histórico americano (1858), porque julgava que o caso tinha uma moral relevante para o público: a lealdade ao monarca que demonstrara Amador Bueno.

Anos 90, Porto Alegre, v. 25, n. 47, p. 221-251, jul. 2018 
${ }^{4}$ Vale mencionar a reedição recente do livro, com um ótimo estudo crítico: Acayaca, 1729, atualização do texto, notas e estudos crítico e biobibliográfico por Valéria Seabra de Miranda e Oscar Vieira da Silva. Belo Horizonte: Ed. PUC Minas: Traquitana, 2004.

${ }^{5}$ A autora inclusive minimiza a opinião de Joaquim Felício de que o Regimento Diamantino inaugurou uma situação de opressão atípica, defendendo que, "Examinando mais detidamente o Regimento, percebe-se que ele pouco trouxe de novo. A maioria de seus parágrafos já estava em vigor, sendo que muitos deles se aplicavam também a regiões exclusivamente auríferas" (FURTADO, 1996, p. 76). ${ }^{6}$ Vide o relato de Alice Dayrell Caldeira Brant, a Helena Morley, em Minha vida de menina, registrando passeios de família ao sítio do Biribiri, da família Felício dos Santos, onde Joaquim passou seus últimos dias.

\section{Referências}

BOCAIÚVA, Quintino. Ideias políticas de Quintino Bocaiúva. Cronologia, introdução, notas bibliográficas e textos selecionados, por Eduardo Silva. Brasília: Senado Federal; Rio de Janeiro, Fundação Casa de Rui Barbosa, 1986, vol. 1.

BOSCHI, Caio. Fontes primárias para a história de Minas Gerais em Portugal. Belo Horizonte: Fundação João Pinheiro, 1998.

BOWERSOCK, Glen Warren; BOWERSOCK, G. W (Ed.). A. D. Momigliano: studies on modern scholarship. Berkeley; Los Angeles: University of California Press, 1994.

CEZAR, Temístocles. Narrativa, cor local e ciência. Notas para um debate sobre o conhecimento histórico no século XIX. História Unisinos. São Leopoldo. v. 8, n. 10, jul./dez. 2004.

. Em nome do pai, mas não do patriarca: ensaio sobre os limites da imparcialidade na obra de Varnhagen. História, São Paulo, v. 24, n. 2, p. 207240, 2005.

- Varnhagen em movimento: breve antologia de uma existência. Topoi, Rio de Janeiro, v. 8, n. 15, jul./dez. 2007. p. 159-207.

COSTA, Célia. O Arquivo Público do Império: o Legado Absolutista na Construção da Nacionalidade. Estudos históricos, Rio de Janeiro, v. 14, n. 26, 2000, p. 217-231.

DIAS, Antônio Gonçalves. Exame nos archivos dos mosteiros e das repartições publicas para a collecção dos documentos historicos relativos ao Maranhão

Anos 90, Porto Alegre, v. 25, n. 47, p. 221-251, jul. 2018 
A geografia da historiografia: o acesso à e o uso da documentação...

por A. Gonçalves Dias. Revista Trimensal do Instituto Histórico e Geográfico Brasileiro, tomo 16, 1853, p. 370-384.

EULÁliO, Alexandre. Joaquim Felício dos Santos, cronista romântico. São Paulo: Jacaremirim Editor, 1976.

FURTADO, Júnia Ferreira. O livro da capa verde: o Regimento Diamantino de 1771 e a vida no Distrito Diamantino no período da Real Extração. São Paulo: Annablume, 1996.

GUIMARÃES, Manoel Luiz Salgado. A disputa pelo passado na cultura histórica oitocentista no Brasil. In: CARVALHO, José Murilo de. Nação e cidadania no império: novos horizontes. Rio de Janeiro: Civilização Brasileira, 2007.

. Livro de Fontes de Historiografia Brasileira. Rio de Janeiro: EdUERJ, 2010.

HARTOG, François. Evidência da História: o que os historiadores veem. Belo Horizonte: Autêntica Editora, 2011.

IGLÉSIAS, Francisco. Historiadores do Brasil. Rio de Janeiro: Nova Fronteira; Belo Horizonte: Ed. UFMG, 2000.

MOMIGLIANO, Arnaldo. As raízes clássicas da historiografia moderna. Bauru: EDUSC, 2004.

NEVES, José Teixeira. Joaquim Felício dos Santos. Estudo Biográfico. In: SANTOS, Joaquim Felício dos. Memórias do Distrito Diamantino. Rio de Janeiro: Edições O Cruzeiro, 1956.

OLIVEIRA, Maria da Glória de. A crítica do fabuloso e a verdade histórica nos estudos de Francisco Adolfo de Varnhagen e Joaquim Manoel de Macedo. Anais do XXVI Simpósio Nacional de História, ANPUH, São Paulo, jul. 2011, p. 2. Disponível em: http://www.snh2011.anpuh.org/conteudo/view?ID_CONTEUDO= 775. Acesso em: maio 2012.

PERES, Marcos Roberto Flamínio. As minas e a agulheta: Romance e História em As minas de prata, de José de Alencar. São Paulo. Tese (Doutorado). USP, 2006.

ROMERO, Sílvio. História da Literatura Brasileira. Rio de Janeiro: Livraria José Olympio Editora, 1960. 6. ed. ROMERO, Nelson (Org.). e Prefácio de. [1ํe edição: 1888]. Tomo Quinto.

SANTOS, Joaquim Felício dos. Acaiaca. Romance indígena. 1729. Ouro Preto: Tipografia do Estado de Minas, 1894.

. Acayaca, 1729. Atualização do texto, notas e estudos crítico e biobibliográfico por Valéria Seabra de Miranda e Oscar Vieira da Silva. Belo Horizonte: Ed. PUC Minas: Traquitana, 2004.

Anos 90, Porto Alegre, v. 25, n. 47, p. 221-251, jul. 2018 
Memórias do Distrito Diamantino. Rio de Janeiro: Edições O Cruzeiro, 1956.

SILVA, Antônio de Moraes. Diccionario da Lingua Portugueza. Quarta edição, reformada, emendada e muito acrescentada pelo mesmo autor: posta em ordem, correta, e enriquecida de grande número de artigos novos e dos sinônimos por Theotonio José de Oliveira Velho. Tomo II F-Z. Lisboa: Impressão Régia, 1831.

SOUZA, Laura de Mello e. Norma e Conflito. Aspectos da História de Minas no século XVIII. Belo Horizonte: Editora UFMG, 2006.

TUCCI, Ugo. Ranke and the Venetian document market. In: IGGERS, Georg G.; POWELL, James M. (Ed.). Leopold von Ranke and the shaping of the historical discipline. Syracuse: Syracuse University Press, 1999, p. 99-107.

VARELLA, Flávia Florentino. Ver e tocar o passado: emoção e sentimento na História do Brasil de John Armitage. História da Historiografia. Ouro Preto, n. 8, abr. 2012, p. 91-106.

VARNHAGEN, Francisco Adolfo de. História Geral do Brasil, antes de sua separação e independência de Portugal. Rio de Janeiro: Em Caza. de E. e H. Laemmert, 1854, tomo I. Utilizamos a edição digitalizada da Biblioteca Brasiliana Guita e José Mindlin. Disponível em: Digital da USP, http://www.brasiliana. usp.br/bbd/handle/1918/01818710. Acesso em: set. 2006.

Recebido em: 10/01/2017.

Aprovado em: 20/09/2017. 
